\title{
Solar flare effects on the geomagnetic elements during normal and counter electrojet periods
}

\author{
R. G. Rastogi ${ }^{1,2}$, B. M. Pathan ${ }^{3}$, D. R. K. Rao ${ }^{3}$, T. S. Sastry ${ }^{4}$, and J. H. Sastri ${ }^{5}$ \\ ${ }^{1}$ Department of Physics, Gujarat University, Ahmedabad 380 009, India \\ ${ }^{2}$ Physical Research Laboratory, Ahmedabad 380 009, India \\ ${ }^{3}$ Indian Institute of Geomagnetism, Mumbai 400 005, India \\ ${ }^{4}$ National Geophysical Research Institute, Hyderabad 500 007, India \\ ${ }^{5}$ Indian Institute of Astrophysics, Bangalore 560 034, India
}

(Received March 4, 1999; Revised August 2, 1999; Accepted August 13, 1999)

\begin{abstract}
The paper describes the study of solar flare effects (sfe) on horizontal $(H)$, eastward $(Y)$ and vertical $(Z)$ components of the geomagnetic field at the Indo-USSR chain of magnetic observatories extending from the magnetic latitudes $0^{\circ}$ to $45^{\circ} \mathrm{N}$, a network not available any where else in the world. Events are selected when strong, normal and reversed (counter) equatorial electrojet are in existence as well as when only a partial counter electrojet is present.

During a strong and normal electrojet event time, $s f e$ consists of a positive impulse in $H$ at all stations, the amplitude of $H$ following the latitudinal variation similar to that of the quiet day monthly mean, $S q(H)$. The $s f e$ in $Y$ is negative at all the stations. Sfe in $Z$ shows positive impulse at the four-electrojet stations and negative at other stations. During a counter electrojet period the effect of solar flare on $H$ field is negative impulse at electrojet stations, positive at low latitude and again negative at stations north of $S q$ focus. Sfe in $Y$ is small at all the equatorial and negative at higher latitude stations. However, $s f e(Z)$ is negative at the equatorial latitudes.

During a partial counter electrojet period the observed effect is the combination of an increase of the planetary current component and the decrease of the electrojet component, giving rise to a negative impulse in $H$ at equatorial stations and a positive impulse in $H$, increasing with increasing distance from the equator. These results are presented and discussed.
\end{abstract}

\section{Introduction}

An interrelation between the optical solar flare and the magnetic crochet was first identified by Carrington (1859) and Hodgson (1859) on September 1, 1859. Dellinger (1935) reported simultaneous occurrence of short wave fade out (SWF) during the crochet time. The concomitant phenomena of solar flare, crochet and short wave fade out soon received much interest of many scientists (Fleming, 1936; Richardson, 1936; Torreson et al., 1936). The effects of solar flares on the geomagnetic field records, vertical incidence pulsed ionosphere sounding records and earth current records all at an equatorial station Huancayo were first described by McNish (1937). He showed that the flare disturbance vectors in $H$ were similar in direction to that of the pre-flare $S q(H)$ vectors. This led to the notion that the crochet current system was mostly the augmentation of the $S q$ current. Nagata (1952) studied the characteristics of solar flare observed at Huancayo, Kakioka and Watheroo. He found that the time from the beginning to the peak as well as the ratio of the magnitudes of the peak crochet deviation to the $S q$ at the corresponding time were nearly the same at the three stations. However, the absolute magnitudes of crochet vari-

Copy right(c) The Society of Geomagnetism and Earth, Planetary and Space Sciences (SGEPSS); The Seismological Society of Japan; The Volcanological Society of Japan; The Geodetic Society of Japan; The Japanese Society for Planetary Sciences. ations at Huancayo were abnormally large as the $S q(H)$ at the same station was.

With the establishment of number of geomagnetic observatories at low latitudes an interest is generated again for the study of crochet. Current systems were drawn for individual solar flares using multi station magnetograms (Veldkamp and Van Saben, 1960; Van Saben, 1961).

Nagata (1966) made a study of the global distribution of 15 typical sfes during the IGY and found an almost perfectly simultaneous relationship between optical and radio solar flares, geomagnetic sfes and the sudden ionospheric disturbances. Ohshio et al. (1967) studied sfe on geomagnetic field on global basis and suggested that the seat of ionospheric current due to solar flares is a little lower than the layer for $S q$ current system. Richmond and Venkateswaran (1971) suggested that the crochet consists of a 'fast' component presumably due to EUV radiation (100-1000 ̊̊) and a 'slow' component produced by soft X-rays (1-100 ̊).

Forbush and Casaverde (1961) first took a proper attention to the crochet at equatorial electrojet region and showed that the enhancement of $s f e$ in $H$ at Peruvian stations varied in a manner similar to the enhancement of $S q(H)$ itself. Rastogi (1965) showed longitudinal inequality in the latitudinal enhancement of $s f e(H)$ amplitude similar to that of electrojet current itself. Srivastava (1974) described a sfe event at $0830 \mathrm{UT}$ on May 3, 1973 recorded at all the 
Table 1. Coordinates and geomagnetic parameters at the Observatories whose data are utilised in this paper during June 1982.

\begin{tabular}{|c|c|c|c|c|c|c|c|c|c|c|c|}
\hline \multirow[t]{3}{*}{ Observatory } & \multirow[t]{3}{*}{ Code } & \multicolumn{2}{|c|}{ Geog } & \multirow{3}{*}{$\begin{array}{c}H \\
\mathrm{nT}\end{array}$} & \multirow{3}{*}{$\begin{array}{l}D \\
\text { o }\end{array}$} & \multirow{3}{*}{$\begin{array}{c}Z \\
\mathrm{nT}\end{array}$} & \multirow{3}{*}{$\begin{array}{l}I \\
\mathrm{o}\end{array}$} & \multicolumn{2}{|c|}{ Sensitivity/mm } & \multirow{3}{*}{$\begin{array}{c}Z \\
\mathrm{nT}\end{array}$} & \multirow{3}{*}{$\begin{array}{l}\text { Chart } \\
\text { speed } \\
\mathrm{mm} / \mathrm{hr}\end{array}$} \\
\hline & & Lat $^{\circ} \mathrm{N}$ & Long $^{\circ} \mathrm{E}$ & & & & & $H$ & Y & & \\
\hline & & & & & & & & $\mathrm{nT}$ & & & \\
\hline Trivandrum & TRD & 8.5 & 77.0 & 39846 & -2.8 & -39 & -0.6 & 2.1 & 1.4 & 2.5 & 20 \\
\hline Ettaiyapuram & ETT & 9.2 & 78.0 & 39850 & -3.0 & 978 & 2.2 & 4.8 & 4.4 & 2.6 & 15 \\
\hline Kodaikanal & KOD & 10.2 & 77.5 & 39190 & -2.4 & 2580 & 3.8 & 2.8 & 16.0 & 12.0 & 15 \\
\hline Annamalai-Nagar & ANN & 11.4 & 79.7 & 40230 & -2.6 & 4414 & 6.3 & 1.8 & 4.0 & 3.1 & 20 \\
\hline Hyderabad & HYB & 17.4 & 78.6 & 39624 & -1.6 & 15347 & 21.1 & 4.5 & 3.5 & 3.7 & 15 \\
\hline Alibag & $\mathrm{ABG}$ & 18.6 & 72.9 & 38190 & -0.7 & 17700 & 24.4 & 1.7 & 1.6 & 1.7 & 20 \\
\hline Ujjain & UJJ & 23.2 & 75.8 & 36969 & -0.5 & 24441 & 33.5 & 1.6 & 1.5 & 2.1 & 20 \\
\hline Jaipur & JAI & 26.9 & 75.8 & 35628 & -0.8 & 29628 & 39.7 & 1.7 & 1.6 & 1.5 & 20 \\
\hline Shillong & SHL & 25.6 & 91.8 & 37409 & -0.8 & 27479 & 36.3 & 1.4 & 4.5 & 2.8 & 20 \\
\hline Sabhawala & $\mathrm{SAB}$ & 30.4 & 77.6 & 33758 & +0.4 & 34499 & 45.6 & 3.3 & 4.9 & 3.4 & 20 \\
\hline Gulmarg & GUL & 34.1 & 74.6 & 31676 & +1.6 & 38919 & 50.9 & 1.5 & 2.4 & 2.2 & 20 \\
\hline Tashkant & TKT & 41.3 & 69.6 & 25670 & +4.7 & 45400 & 60.1 & 3.2 & 3.2 & 2.1 & 20 \\
\hline Alma Ata & AAA & 43.3 & 76.9 & 25270 & +4.5 & 47920 & 62.2 & 3.0 & 3.0 & 2.0 & 20 \\
\hline Koraganda & KGD & 49.8 & 73.1 & 20120 & +1.8 & 52370 & 68.9 & 3.0 & 3.0 & 2.0 & 20 \\
\hline Novarabersk & NVS & 55.1 & 82.9 & 17130 & +0.5 & 52570 & 71.9 & 1.9 & 2.1 & 3.2 & 20 \\
\hline
\end{tabular}

three components of the geomagnetic field $D, H$ and $Z$ at Indian Observatories. The amplitude of $s f e$ in $H$ was found to be smaller at equatorial electrojet stations Annamalainagar, Kodaikonal and Trivandrum compared to those at non-jet stations, Hyderabad, Alibag and Sabhawala. Rastogi et al. (1975) showed that this anomaly in the latitudinal distribution of amplitude in $s f e(H)$ is due to a partial counter electrojet being in existence during the period of the solar flare.

Utilising the Indian geomagnetic data, the sfe was extensively studied and complexities are well discussed by Raja Rao and Rao (1963), Rastogi et al. (1975), Sastri (1975), Rangarajan and Rastogi (1981), Rastogi et al. (1983), Rastogi (1996) etc. Some of the above studies also considered the ionospheric data to explain the flare effects.

Since 1975, a chain of nine magnetic observatories has been operating in India extending from the latitude of the center of the electrojet to the latitude of $S q$ focus. Stations north of $S q$ focus in former USSR states supplement this. The data from these observatories provide a unique possibility of studying the detailed latitudinal effects of solar flares along a restricted longitude sector. Rastogi et al. (1997) have described the effect of an intense solar flare event at 1311 LT on 15 June 1991 at Indian stations. The solar flare effects appeared to be an augmentation of the ionospheric current system existing at the time of the flare. $\Delta H(s f e)$ was positive at all stations and decreased progressively with latitude. $\Delta Y$ (sfe) were negative at all the stations, $\Delta Z(s f e)$ were positive at equatorial and negative at non-electrojet observatories. In this communication, it is aimed to describe the flare events under varied equatorial electrojet conditions employing the observations that were made in the unique Indo-USSR network of observatories.

\section{Observations}

The stations whose data are utilised are shown in Fig. 1(a) and are listed in Table 1 together with other relevant facts about the stations. It may be noted that the speed of the magnetograms was $15 \mathrm{~mm} / \mathrm{hr}$ at Kodaikanal, Ettaiyapuram and Hyderabad while at all other stations it was $20 \mathrm{~mm} / \mathrm{hr}$. These examples of crochet were selected during June 1982 from the published IAGA listing.

In Fig. 1(b), are shown the mean solar daily variations on five international quiet days $S q$ of $Y, H$ and $Z$ fields at each of the stations for the month of June 1982. $Y$ at TRD showed a small positive deviation around $06 \mathrm{hr}$ and a prominent negative deviation at $12 \mathrm{hr}$. With increasing distance from the equator the morning peak becomes stronger such that at GUL both the morning maximum and noon minimum are almost equal in magnitude. At stations north of GUL $\Delta Y$ was maximum at $07-08 \mathrm{hr}$ and minimum at $13-14 \mathrm{hr}$. $\Delta H$ at TRD showed a minor minimum around $06 \mathrm{hr}$ and a larger maximum around $11 \mathrm{hr}$. With increasing latitude, the magnitude of the midday peak decreased and at SAB and GUL a minimum at 09 and a maximum at $14 \mathrm{hr}$ was observed. At GUL $\Delta H$ showed a minimum of $-23 \mathrm{nT}$ at 09 and a maximum of $24 \mathrm{nT}$ at $13 \mathrm{LT}$. At stations north of GUL, $\Delta H$ showed a strong minimum around noon hours. $\Delta Z$ at TRD showed a maximum in the forenoon (10 LT) and a minimum in the afternoon (15 LT) similar but decreased variation was observed at ETT. At ANN a prominent mini- 


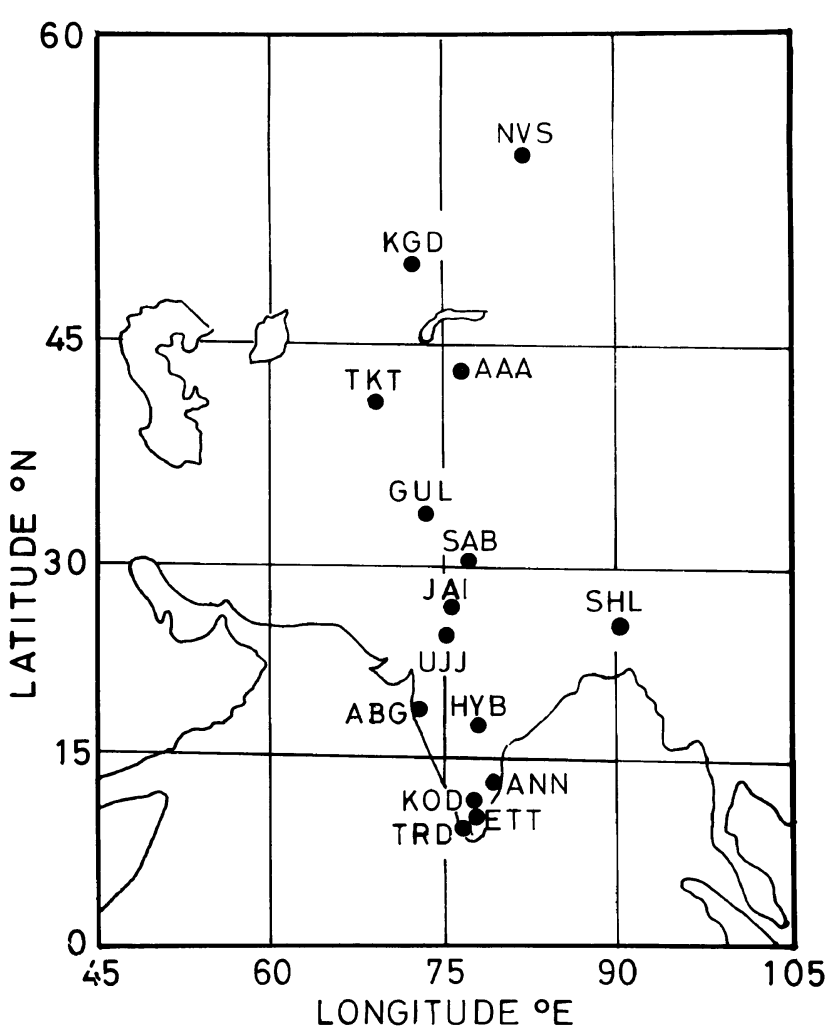

Fig. 1(a). Location map of geomagnetic observatories. The abbreviations of observatories are defined in Table 1.

mum was observed suggesting the station is at the fringe of the electrojet. At other stations the prominent feature was a minimum around midday. The $\Delta H$ (TRD-ABG) characterizing the strength of the electrojet current showed a midday peak of $30 \mathrm{nT}$ and a partial counter electrojet effect around $15 \mathrm{hr}$, even in monthly mean quiet day variations.

Fukushima (1993) has shown that the daily variation of $Z$ field at Koror followed the temporal gradient in $H$ field and hence concluded that $Z$ was affected by the induction effects due to ocean currents. The abnormal variation of $\Delta Z$ at Trivandrum has been attributed to the increase electromagnetic induction due to ocean currents by Nityananda et al. (1977) and Srivastava and Abbas (1978); and due to conducting channel between India and Sri Lanka by Rajaram et al. (1979). From the present curves of $S q(Z)$ it is to be noted that whatever may be reasons for induction, the effect is present at Trivandrum (by abnormal diurnal variation of the element) and to a lesser extent at Ettaiyapuram. At Kodaikanal and Annamalainagar, the effects due to the electrojet currents appear to be much stronger than that of induction.

\subsection{Crochet on 4 June 1982 (normal electrojet day)}

In Fig. 2 are reproduced the $Y, H$ and $Z$ tracings of the magnetograms on 4 June 1982 at the station at the centre of electrojet, TRD, near the edge of the electrojet, ANN, and a station well outside the range of electrojet, UJJ. The traces are so reproduced that an upward movement of the trace indicates the increase of either of the components of the field, $H, Y$ or $Z$. The sensitivities of individual traces are also indicated and it is to be noted that these are not uniform.
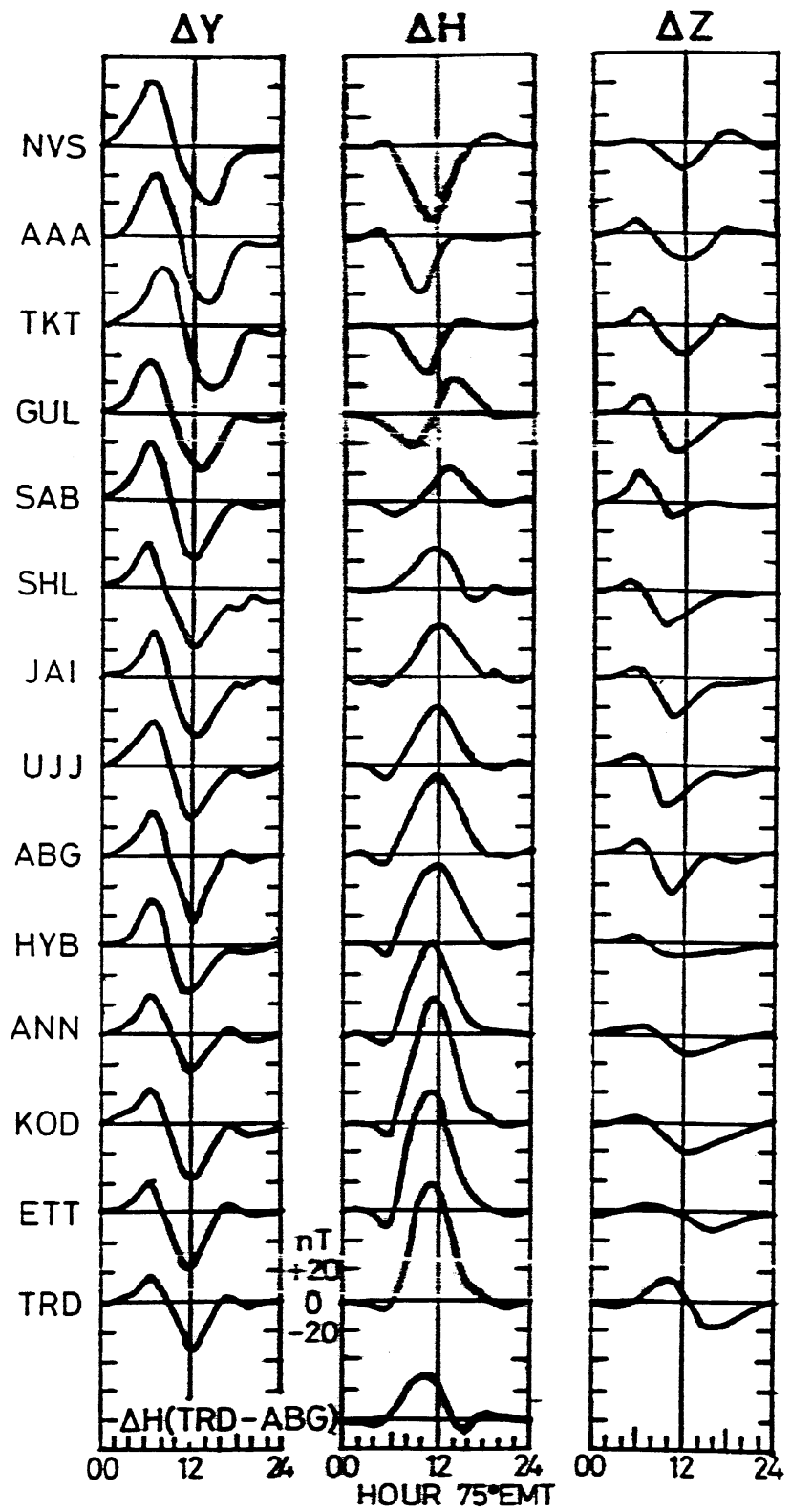

Fig. 1(b). Monthly mean solar daily variations of $\Delta Y, \Delta H$ and $\Delta Z$ at each of the stations for the month of June 1982.

The solar daily range of $H$ on this day is estimated to be $73 \mathrm{nT}$ at TRD compared to $S q$ (monthly mean) of $79 \mathrm{nT}$. Thus, the day is classified as a normal electrojet day. Two solar flares have occurred at 1006 and $1131 \mathrm{hr}$ at $75^{\circ} \mathrm{E}$ time. At TRD, the flares have produced positive crochets in $H$ and $Z$ and a small negative impulse in $Y$ traces. At ANN, similar positive impulses in $H$ and $Z$ and negative impulses in $Y$ fields are recorded. At UJJ, the sfe impulses are positive in $H$ and negative for $Z$ and $Y$ fields. It is to be noted that the sign of the sfe impulses at all the stations correspond to the sign of the component with respect to the early morning (or midnight) field values. Thus this example confirms the earlier results that solar flare effects are primarily the augmentation of the ambient current system.

Next the deviations of $H, Y$ and $Z$ just prior to the flare are estimated with respect to the midnight values and are designated as $\Delta H o, \Delta Y o$ and $\Delta Z o$ respectively. The amplitudes 


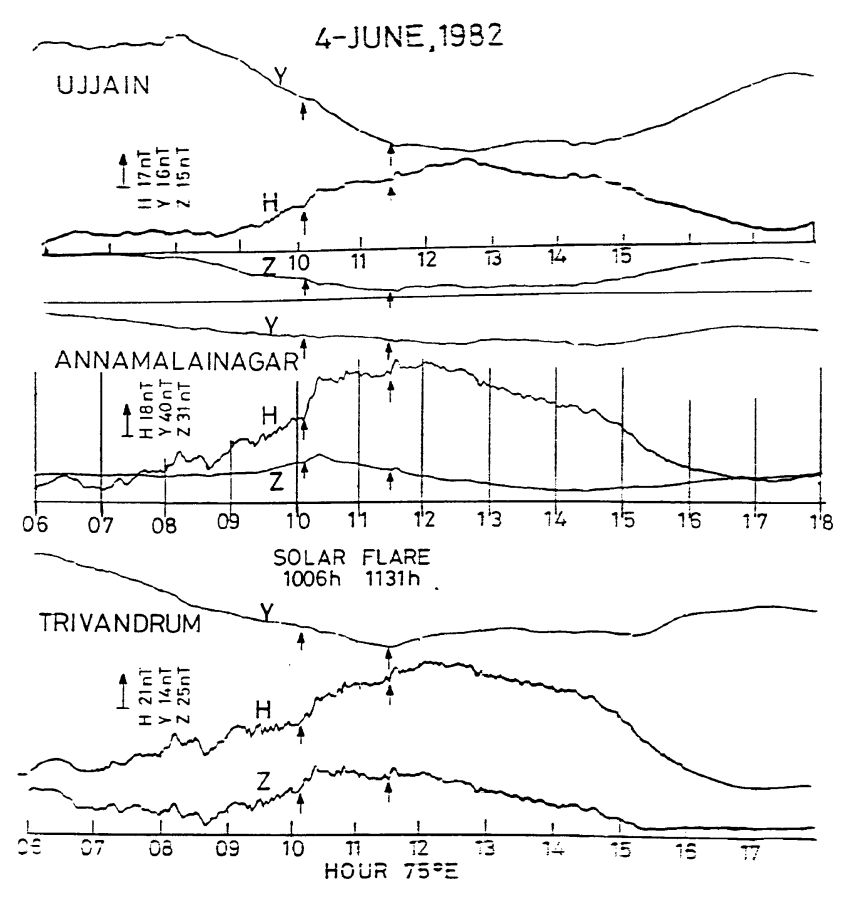

Fig. 2. Tracings of the magnetograms at Trivandrum, Annamalainagar and Ujjain on 4 June 1982 showing solar flare effect at $1006 \mathrm{hr}$ and $1131 \mathrm{hr}$ $75^{\circ}$ EMT.

( from starting time of the flare to its peak on the magnetogram) are scaled in $H, Y$ and $Z$ fields and are denoted as $\Delta H f, \Delta Y f$ and $\Delta Z f$ respectively. In Fig. 3 are shown the latitudinal variations of $\Delta H o, \Delta Y o$ and $\Delta Z o$ and $\Delta H f$, $\Delta Y f$ and $\Delta Z f$ for both the flares. As the flares occurred at the time close to local noon, the $\Delta H o$ has shown enhancement at low latitudes. The magnitudes of $s f e$ in $H$ indicate systematic increase towards the equator. The magnitudes of $\Delta Y_{o}$ before the impulse were negative at low latitudes and positive at stations north of the Indian latitudes for the first flare. The impulses due to solar flare were negative at the equatorial and low latitude stations and slightly positive at higher latitude stations. The latitudinal variations of $\Delta Z o$ showed positive values at equatorial station TRD, ETT, KOD and $\mathrm{ANN}$ and negative value at $\mathrm{ABG}$ and other higher latitude stations. The solar flare impulse in $Z$ showed very small value at low and higher latitude stations but at equatorial latitude stations $\Delta Z f$ were uniformly positive with measurable magnitudes.

\subsection{Crochets on 5 June 1982 (strong normal electrojet day)}

Three solar flares occurred at $0627 \mathrm{hr}\left(75^{\circ} \mathrm{E}\right.$ time $), 1115$ hr and 1227 on 5 June 1982. Figure 4 shows the daily variations of $\Delta Y, \Delta H$ and $\Delta Z$ on 5 June 1982. It is seen that on this day the ionospheric currents were abnormally larger than the monthly mean values. The values of $\Delta H$ (TRD-ABG) are negative around sunrise period but are exceedingly large and positive during the rest of the day. $\Delta H$ at stations north of GUL has shown midday minimum. The daily variations of $\Delta Y$ as well as $\Delta Z$ are also larger at equatorial stations KOD and ANN as expected because of the enhanced eastward electrojet currents during the daytime hours. The daily variations of $Z$ field at TRD and ETT have a peak in the

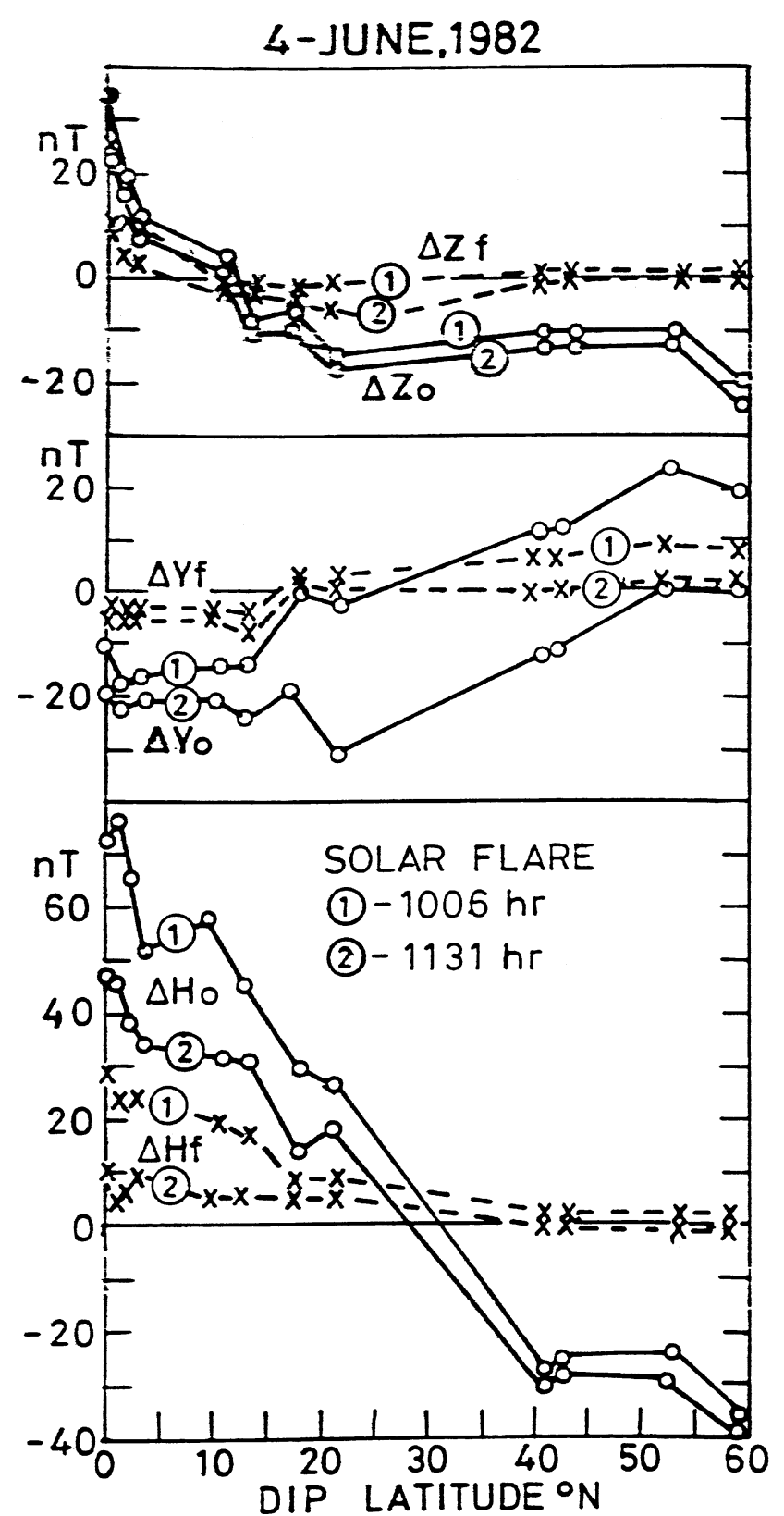

Fig. 3. Latitudinal variations of the pre-flare amplitudes and $s f e$ amplitudes in $H, Y$ and $Z$ associated with two flares on 4 June 1982.

forenoon and a minimum in the afternoon hours, a feature generally attributed to the effect of induction within the conducting regions of the solid earth.

In Fig. 5 are shown the latitudinal variations of $\Delta H, \Delta Y$ and $\Delta Z$ on 5 June 1982, in comparison with the corresponding values for monthly mean $S q$ variation. It is seen that the range of $H$ field at low latitudes is larger on 5 June 1982 when compared to the monthly mean $S q$ variations. At the electrojet stations, TRD and ETT the range in $H$ is more than double the monthly mean value. Similar enhancements of $\Delta Y$ are observed at the equatorial stations on this day. The $\Delta Z$ near noon is positive at TRD and ETT and negative at other stations.

In Fig. 6 are reproduced the traces of $H, Y$ and $Z$ fields at each of the stations on 5 June 1982. The first crochet oc- 


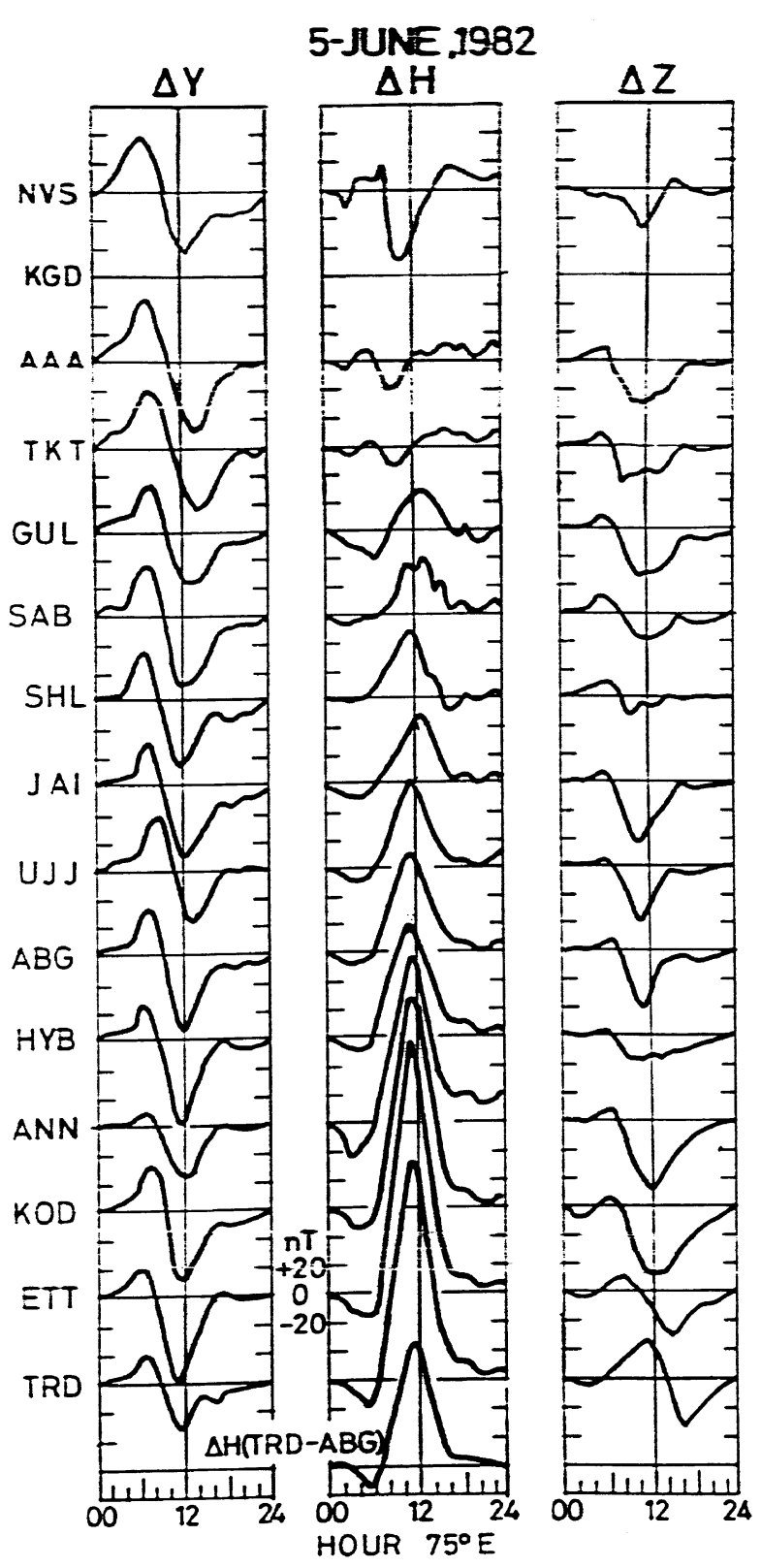

Fig. 4. Solar daily variations of $\Delta Y, \Delta H$ and $\Delta Z$ at each of the stations on 5 June 1982. The $H$ on this day was distinctly larger than the corresponding $S q$ variations.

curred around the sunrise period (0627 hr) when $\Delta H$ (TRD) was negative at the equatorial latitudes and consequently the impulse of crochet on $H$ at TRD, ETT, KOD and ANN were all negative. At higher latitudes, no significant $s f e$ were seen due to almost zero $\Delta H$ fields at that time. At stations north of India, the impulse was clearly positive. The signatures of this flare on $Y$ field were too small at the northern latitude stations. The sfe in $Z$ were small and positive at TKT and AAA.

Another two solar flares occurred at $1115 \mathrm{hr}$ and $1227 \mathrm{hr}$ when the normal electrojet current was quite strong. The signatures of the crochet on $H$ are consequently positive at each of the stations from Trivandrum to AlmaAta and negative at Karaganda and Novosobirsk following the $S q$ current pattern. It is to be noted that the signatures of crochet on $Y$

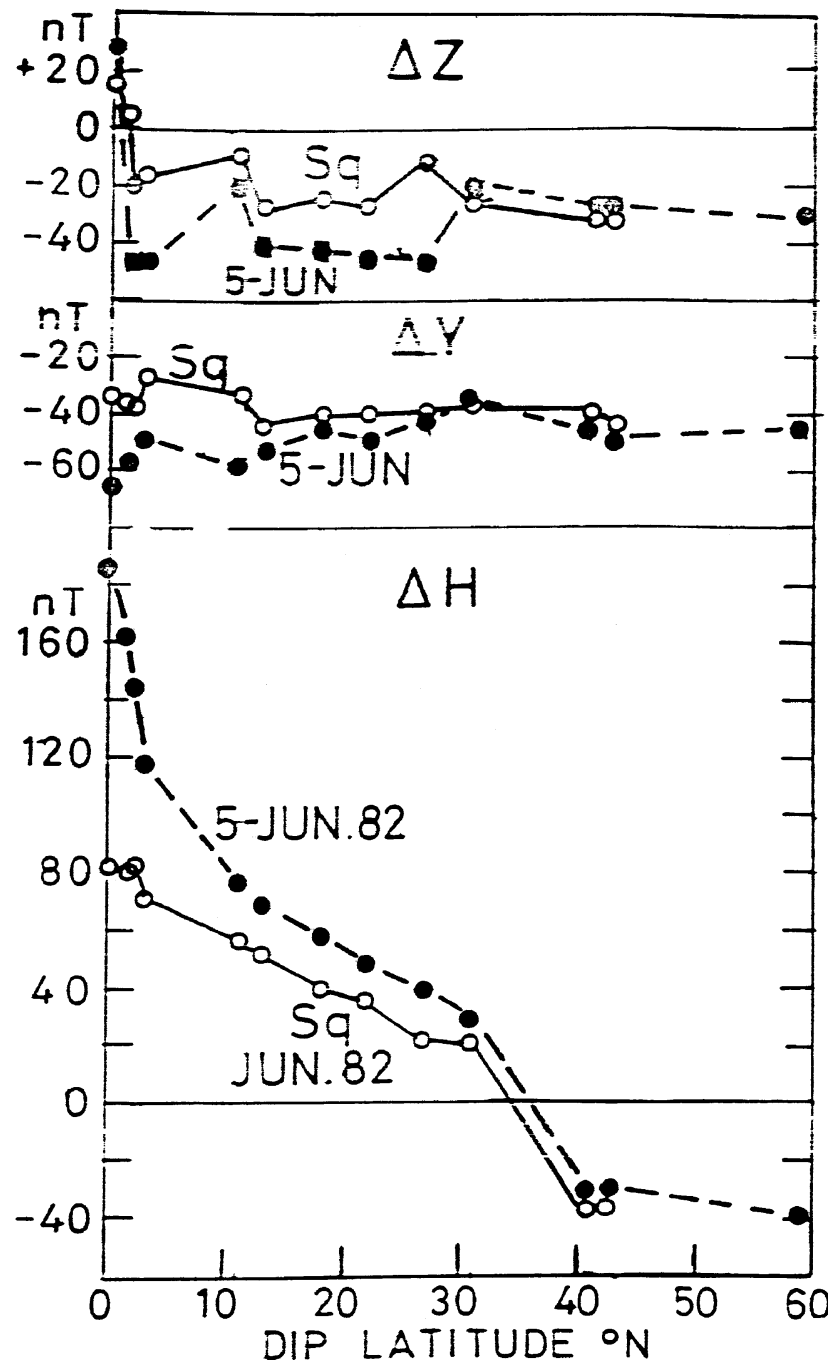

Fig. 5. Latitudinal variations of the daily ranges of $\Delta H, \Delta Y$ and $\Delta Z$ on 5 June 1982 compared with the corresponding variations on $S q$ days.

were negative at all the stations. The signature of crochet on $Z$ was positive at equatorial stations TRD, ETT, KOD and $A N N$, and negative at stations outside the electrojet belt. The effect of $s f e$ in $Z$ at HYB was too small to ascertain the sign correctly. It is to be noted that the positive deviations of $\triangle Z o$ at TRD and ETT have been extended even upto midday hours on this day.

In Fig. 7 are shown the latitudinal plots of the pre-flare values of $\triangle H o, \triangle Y o$ and $\triangle Z o$ and the sfe magnitudes in these fields $\Delta H f, \Delta Y f$ and $\Delta Z f$ for the two flares (1) at $1115 \mathrm{hr}$ and (2) at $1227 \mathrm{hr}$. It is seen that the pre-flare $\Delta H o$ for both the first and second have shown a strong enhancement over the magnetic equator. The solar flare effect in $H$ is the same enhancement towards the equator. The pre-flare $\Delta Y o$ is around -30 and $-40 \mathrm{nT}$ at all the stations. The flare magnitude in $Y(\Delta Y f)$ at all the stations are around $-10 \mathrm{nT}$. The value of $Z$ field just before the flare, $\Delta Z o$ has indicated an increase, from a value of -40 at Jaipur to a value around $+15 \mathrm{nT}$ at Trivandrum. The flare effect in $Z$, i.e. $\Delta Z f$ is around $-5 \mathrm{nT}$ to $-10 \mathrm{nT}$ at low and higher latitude stations. But between ANN and TRD, it showed an increase from a value of +30 to $+40 \mathrm{nT}$. Thus, the $s f e$ in $Z$ at the equatorial 


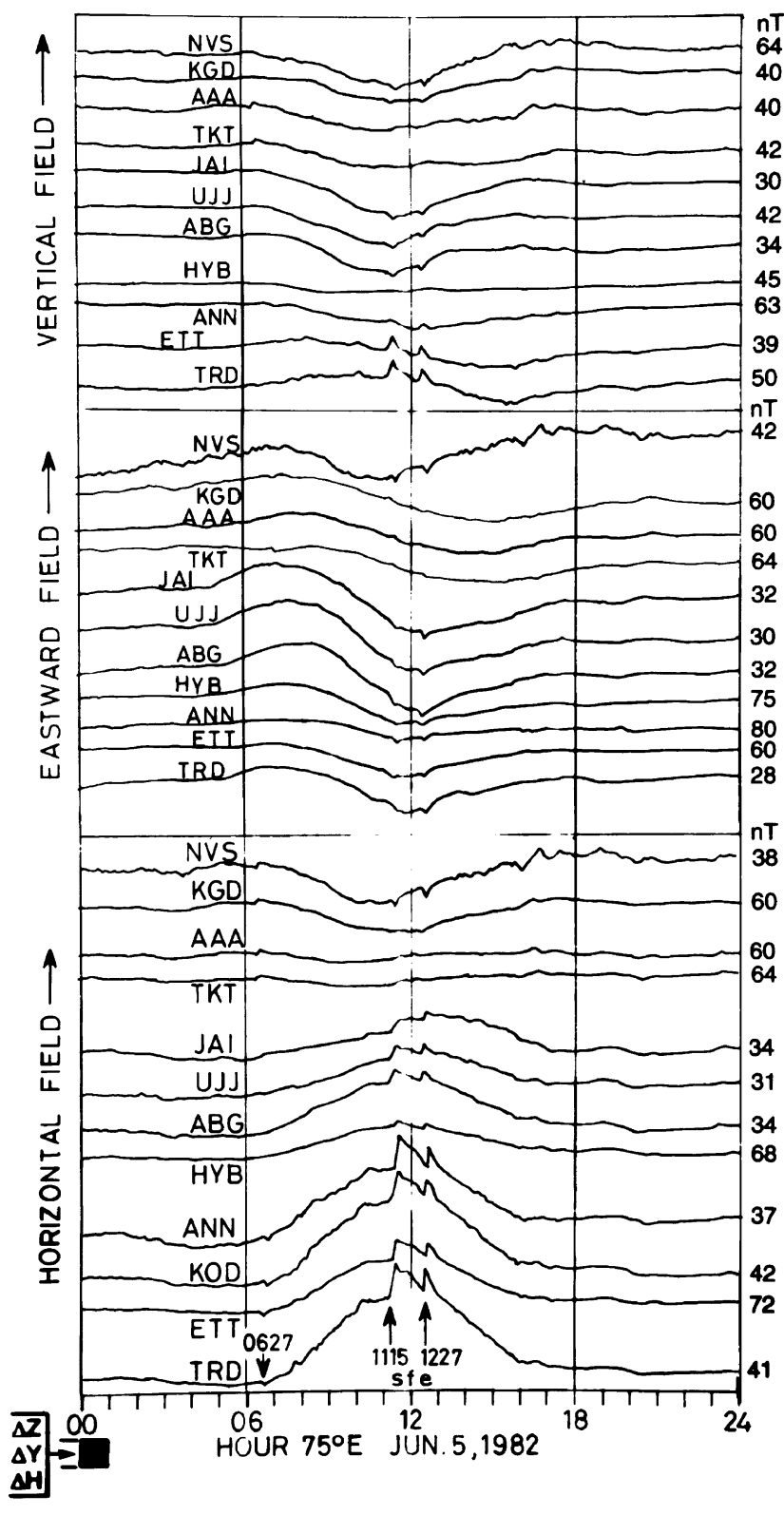

Fig. 6. Reproduction of the traces of $H, Y$ and $Z$ magnetograms on 5 June 1982 at different stations showing the signature of the effects of solar flares at 0627,1115 and 1227 LT. The magnitude of the field change is indicated as vertical side of a square included in the diagram. The side of the square is the same as one hour duration.

stations can be considered as abnormally large.

\subsection{Crochet on 15 June 1982 (strong counter electrojet day)}

A solar flare has occurred at $1520 \mathrm{hr}$ on 15 June 1982. The daily variations of $\Delta H, \Delta Y$ and $\Delta Z$ on 15 June 1982 are shown in Fig. 8. The range of $H$ at TRD on 15th June 1982 was very close to the monthly mean values. The flare occurred in the afternoon hours when $\Delta H$ at TRD was significantly negative over the midnight level. The value of $\Delta H$ (TRD-ABG) was negative exceeding $40 \mathrm{nT}$ during the flare. This event was thus during a full strong counter electrojet conditions.

In Fig. 9 are reproduced vertical incidence ionograms at Kodaikanal from $1500 \mathrm{hr}$ to $1600 \mathrm{hr}$ on $15 \mathrm{June}$ 1982. It is

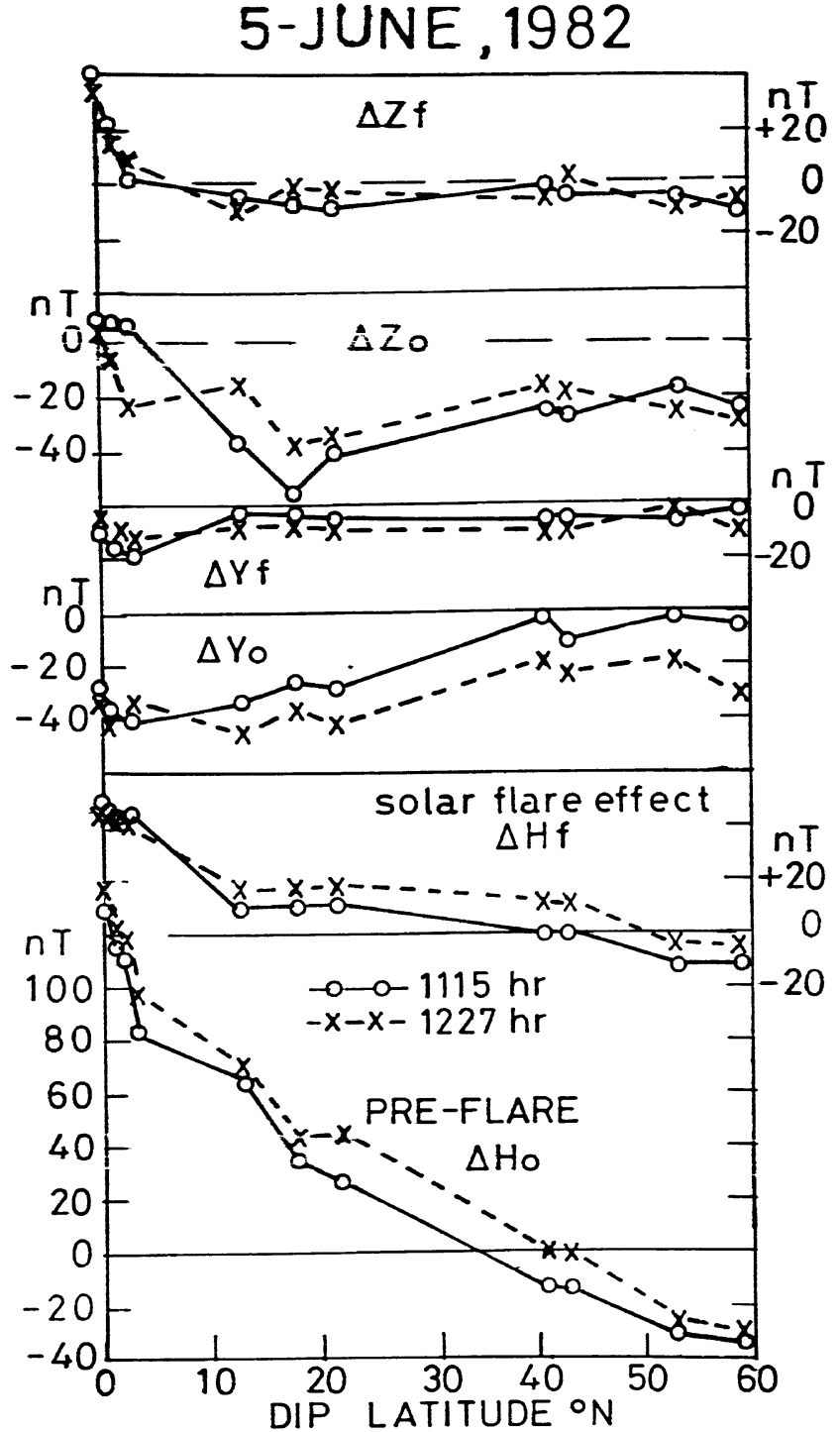

Fig. 7. Latitudinal variations of pre-flare values $(\triangle H o, \Delta Y o$ and $\Delta Z o)$ of the flare impulse $(\Delta H f, \Delta Y f$ and $\Delta Z f)$ of the flares at 1115 and 1227 LT on 5 June 1982.

to be noted that at 1500 and $1515 \mathrm{hr}$ echoes were recorded from frequencies lower than $2 \mathrm{MHz}$. At $1530 \mathrm{hr}$ no echo was seen below $6 \mathrm{MHz}$ and even the reflections at higher frequencies were weak. Noting that the flare had stated at $1520 \mathrm{hr}$, this absence of low frequency echoes are due to the sudden increase of ionospheric absorption due to the flare ionization at lower $E$ and $D$ regions. The absorption decreased on subsequent records at $1545 \mathrm{hr}$ and $1600 \mathrm{hr}$.

Figure 10 shows the reproduction of the $H, Y$ and $Z$ traces of the magnetograms at each of the stations on 15 June 1982. This seems to be a very rare occasion when the flare occurred during strong counter electrojet event and a set of data at all the stations in India and former USSR states are available. The signature of $\Delta H f$ due to crochet is significantly negative at the equatorial stations TRD, ETT, KOD and ANN. It is positive at all stations at higher latitude upto TKT and negative at KGD and NVS. The signature of $\Delta Z f$ was very clearly negative at TRD and ETT and positive at ANN, HYB and at other stations in India. $\Delta Z f$ is again positive at sta- 
$.15-J U N .1982$

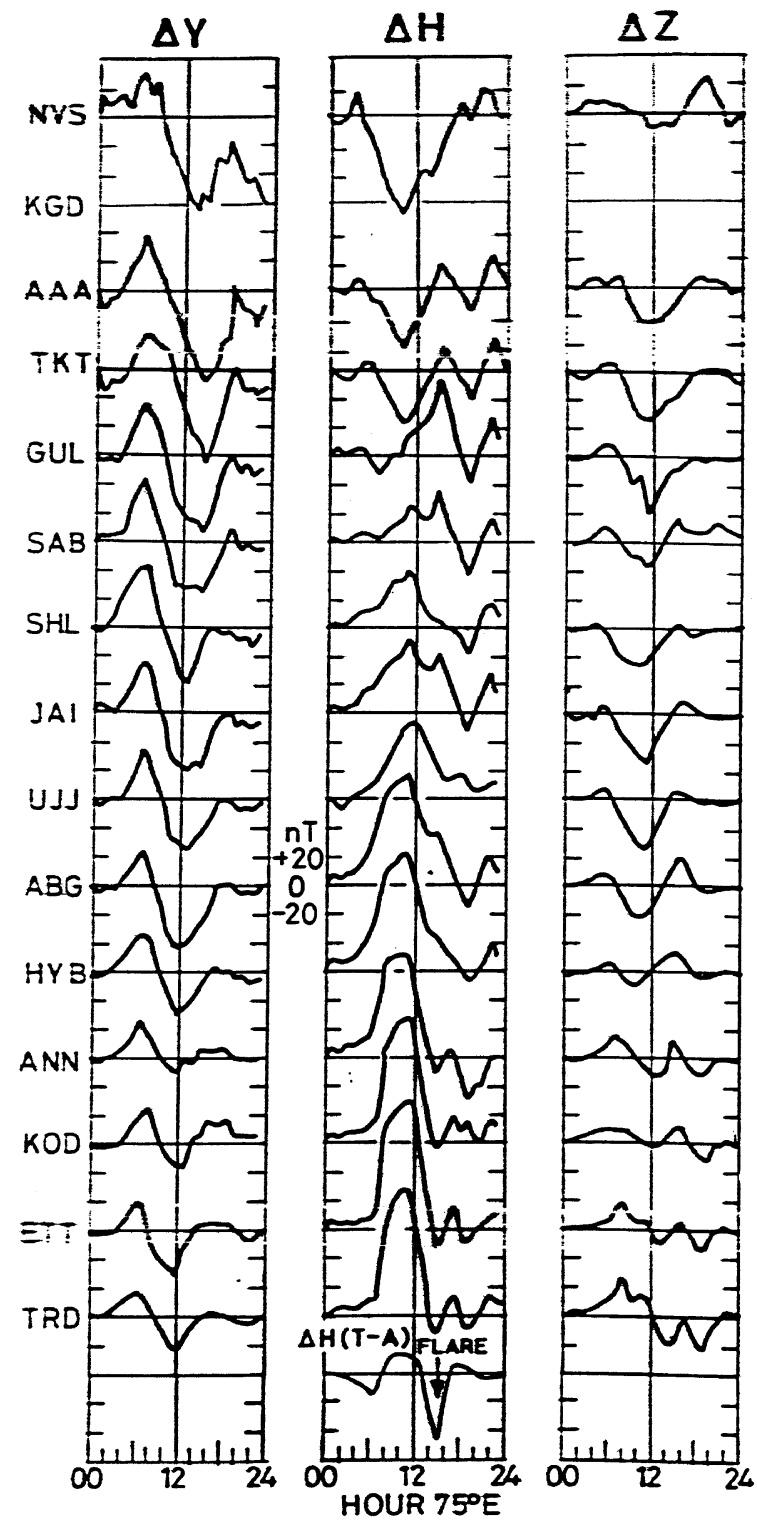

Fig. 8. Solar daily variations of $\Delta Y, \Delta H$ and $\Delta Z$ at each of the stations on 15 June 1982, a solar flare had occurred at 1520 LT during a counter electrojet event.
KODAKANAL 15-JUN,1982
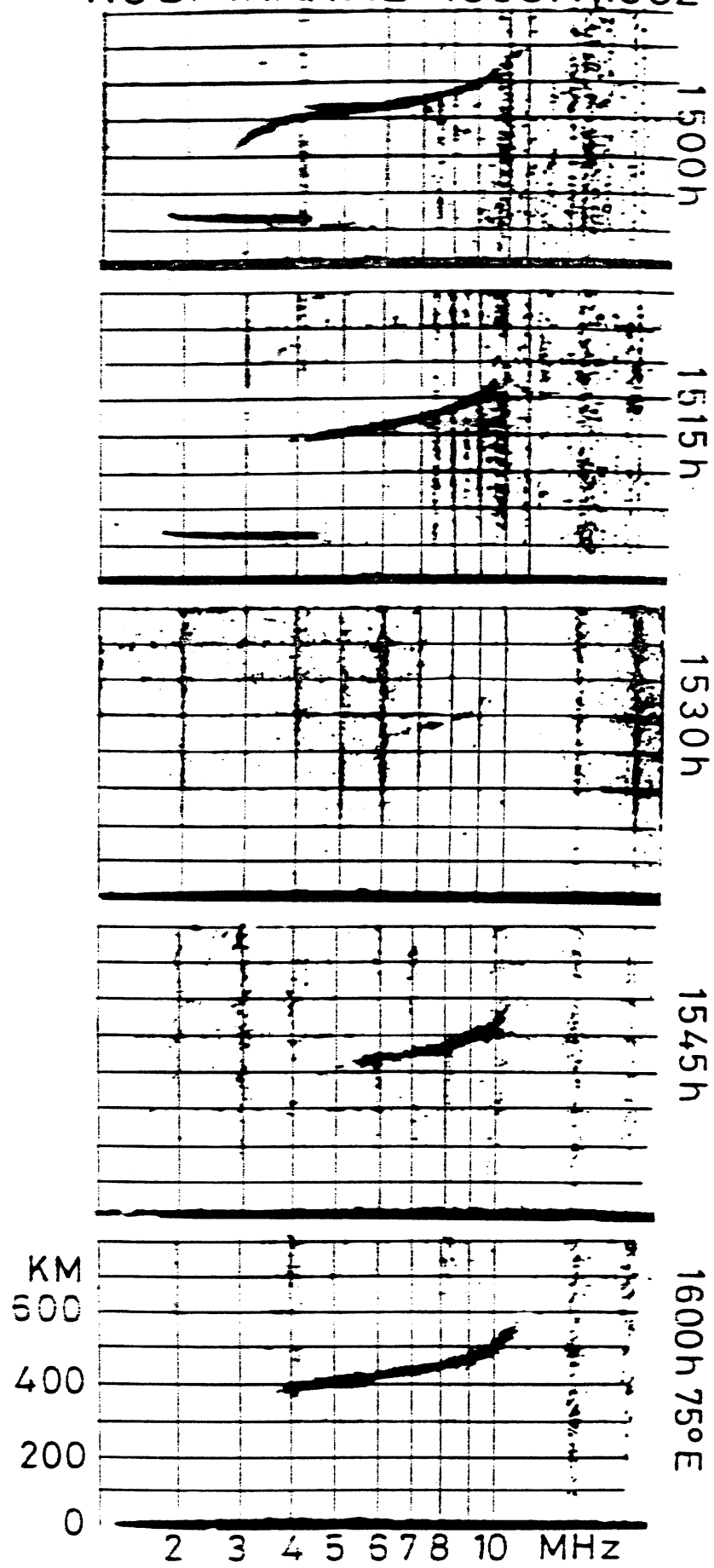

Fig. 9. Reproduction of the vertical incidence ionospheric p'-f records at Kodaikanal on 15 June 1982 around the time of flare which occurred at $1520 \mathrm{hr} 75^{\circ} \mathrm{EMT}$

values of $\triangle H o, \triangle Y o$ and $\triangle Z o$ as well as the amplitude of crochet $\Delta H f, \Delta Y f$ and $\Delta Z f$. It is remarkable to note that the latitudinal variations at $\Delta H o$ as well as $\Delta H f$ show decreasing trend with decreasing latitude. The actual values of $\Delta H o$ and $\Delta H f$ at TRD, ETT, KOD and ANN are negative but the effect of the counter electrojet is evidenced at all the other stations in India. It has been shown earlier that the effect of very strong counter electrojet is not confined only to the stations at equatorial latitudes but can extend upto the northernmost station in India (Rastogi, 1991). The latitudinal variations of $\Delta Z$ and $\Delta Y$ are very similar just prior to the onset and at the peak of crochet.

\subsection{Crochet on 3 June 1982 (a partial counter electrojet day)}

A crochet occurred at $1642 \mathrm{hr}$ on 3 June 1982. Figure 12 shows the $S q$ daily variations of $H, Y$ and $Z$ at all the stations on 3 June 1982. The electrojet on this day was close to the monthly mean value. $\Delta H$ (TRD) was positive at the time of the solar flare but $\Delta H$ (TRD-ABG) was negative, suggesting a partial counter electrojet condition during the flare. In 


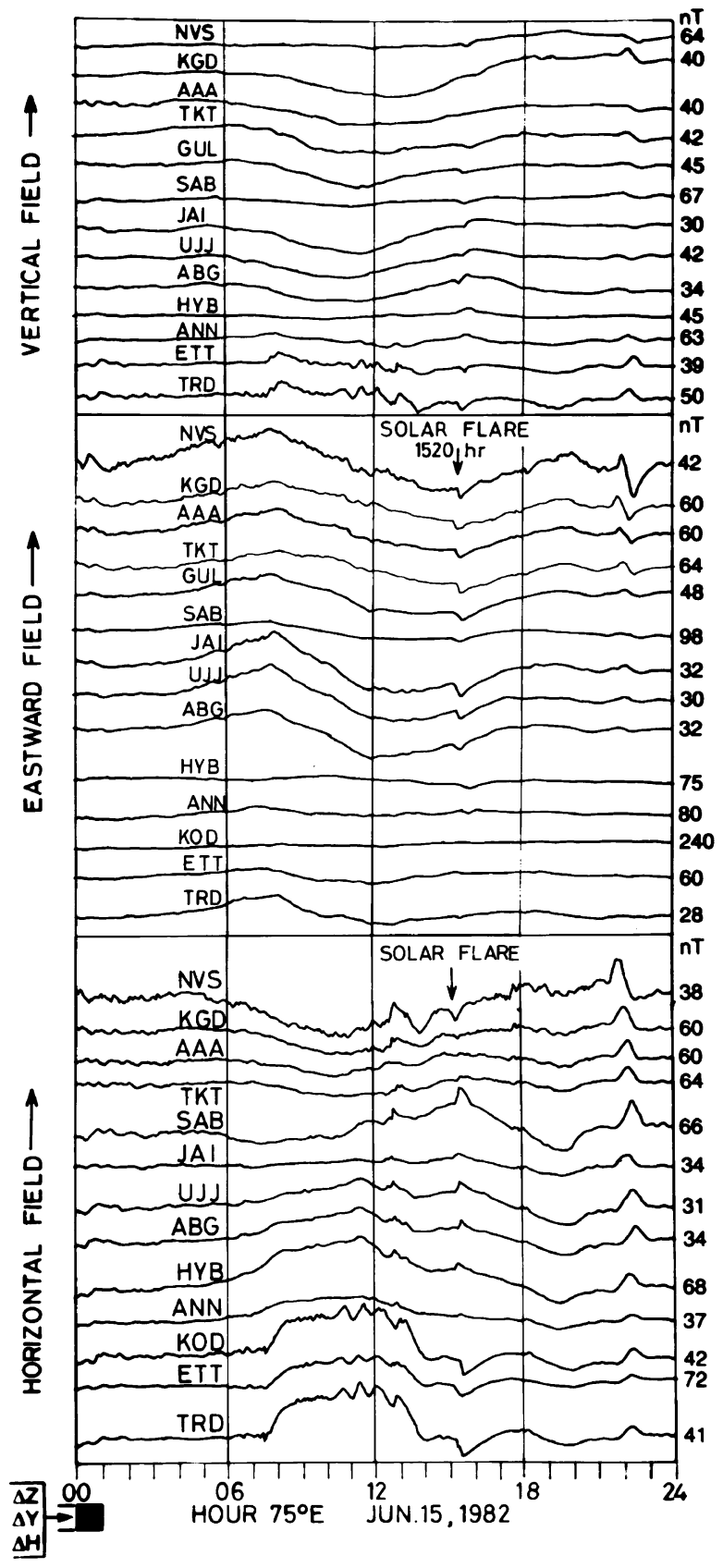

Fig. 10. Same as Fig. 6 but for 15 June 1982. The flare occurred at 1520 LT.

Fig. 13 are reproduced the traces of $H, Y$ and $Z$ at each of the stations. It is to be noted that the crochet signature in $H$ is a negative one at all the equatorial stations TRD, ETT, KOD and ANN while positive amplitude resulted at other non-equatorial stations. $\Delta Y$ due to the crochet is positive at the equatorial stations and negative at UJJ, JAI and GUL while an insignificantly small value is recorded at HYB and ABG. The signature of $\Delta Z$ appears to be positive at equatorial and negative at higher latitudes. Figure 14 shows the latitude variations of the pre-flare signatures $\triangle H o, \triangle Y o$ and $\Delta Z o$ as well as flare impulse $\Delta H f, \Delta Y f$ and $\Delta Z f$. The pre-flare values of $\Delta H o$ were practically constant with latitude suggesting that there was a partial counter electrojet when $\Delta H$ (TRD) was positive but $\Delta H$ (TRD-ABG) was

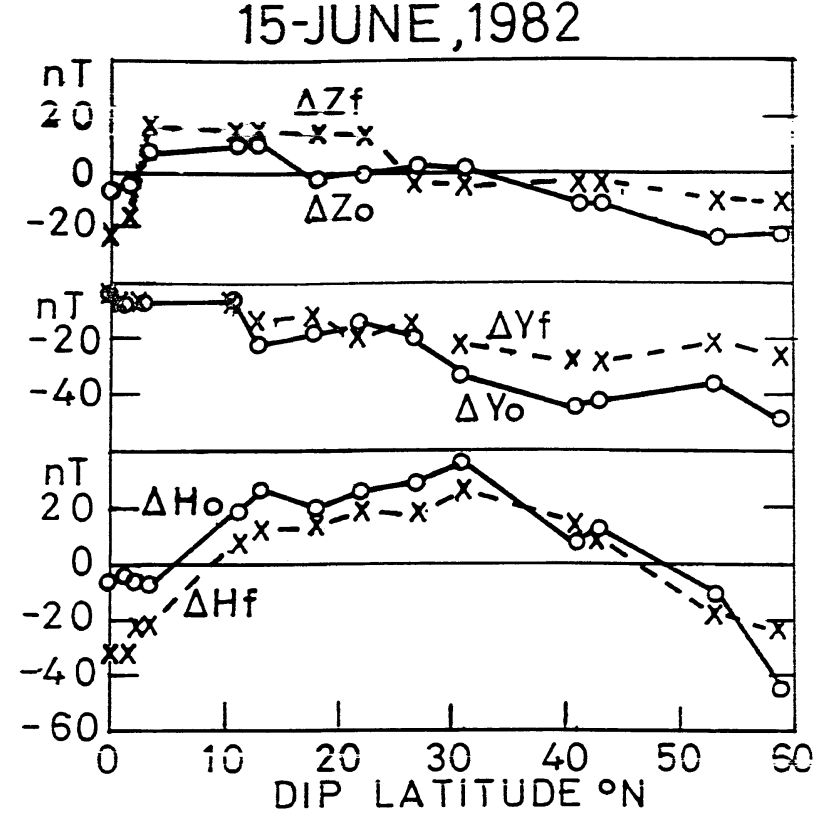

Fig. 11. Latitudinal variations of the pre-flare values $(\Delta H o, \Delta Y o$ and $\Delta Z o)$ and peak flare values of peak flare impulses $(\Delta H f, \Delta Y f$ and $\Delta Z f)$ of the flare at 1520 LT on 15 June 1982 during a counter electrojet period.

negative. Rastogi (1975) has explained these events as due to the superimposing of a westward flowing current at 100 $\mathrm{km}$ altitude over the global $S q$ current flowing eastward at $107 \mathrm{~km}$, such that the net current is weakly eastward. The latitudinal variations of $H$ are greatly reduced during these events. The signature of crochet on $H$ shows decreasing amplitude from ABG to TRD in conformity to the characteristics of partial counter electrojet. The values of pre-flare $\Delta Y o$ are positive at each of the stations while the flare signature is positive at low latitudes and negative at higher latitudes. The pre-flare values of $\Delta Z o$ are positive at each of the stations again indicating a westward flowing electrojet current.

\section{Results and Discussions}

The effect of solar flare on the geomagnetic field has been, since the earliest work, assumed to be a simple augmentation at the pre-flare ionospheric currents over the station. There has been little attention paid to the $s f e$ on $Z$ field due to uncertain induction effects on this component of the geomagnetic field. However, the flare is a temporary increase of solar ionization as such we assume there will be no significant change in electric fields. These sfes can be very useful in understanding the electromagnetic induction effects on the various components of the fields at the station. The unique Indo-USSR chain of magnetic observatories provide data for the ionospheric current system not available anywhere else in the world.

The solar flare occurring during the period of strong eastward currents at low latitudes produce positive impulse in $H$ field at all the stations. The magnitudes of $\Delta H$ due to $s f e$ follow the latitudinal variation very similar to that of $S q$ $(H)$. The $s f e$ for the midday events on the eastward field $(\Delta Y)$ show a negative impulse at all the stations. The $s f e$ in $Z$ results in an abnormal positive impulse at electrojet 


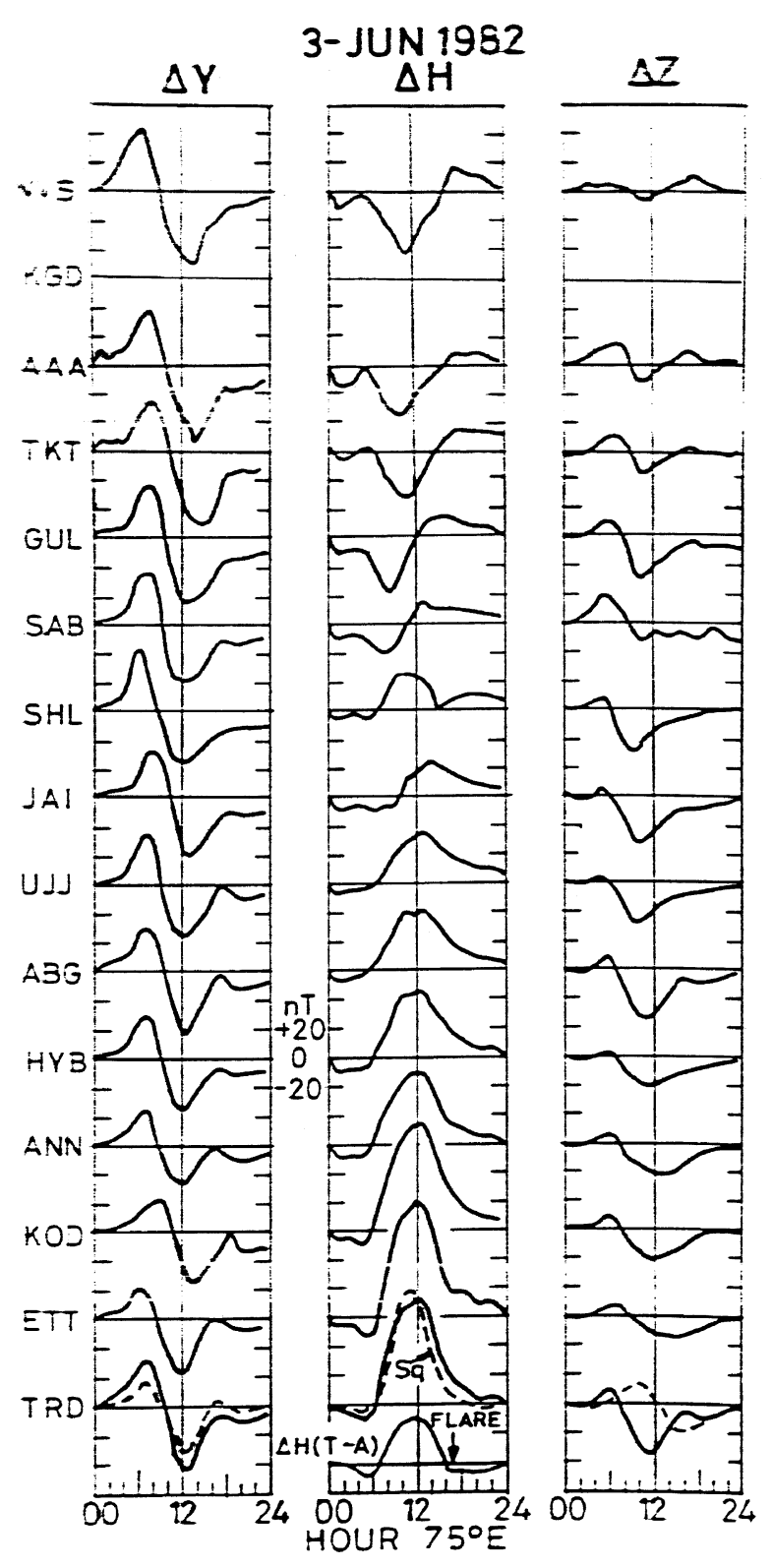

Fig. 12. Solar daily variations of $\Delta Y, \Delta H$ and $\Delta Z$ at each of the stations on 3 June 1982, a solar flare had occurred at 1642 LT when a partial counter electrojet period

stations, TRD, ETT, KOD and ANN eventhough induction effects may not distinctly be seen at KOD or ANN on $S q(Z)$ variations. This is due to the shorter period of $s f e$ duration compared to that of $S q$ variation, and the induction effects are well known to be stronger and sensitive for shorter period variations (Carlo et al., 1982).

The solar flare effect in $H$ during the interval of strong counter electrojet consist of a negative impulse at all the electrojet stations and a positive impulse at low latitude stations outside the electrojet belt. This can be understood as the ionospheric current, during counter electrojet period, is reversed to westward direction over the equatorial stations but remains eastward at other low latitude stations. The effect of solar flare during a counter electrojet period on $Y$ shows negative impulse at low latitude stations and insignificantly small negative impulse at equatorial stations. During

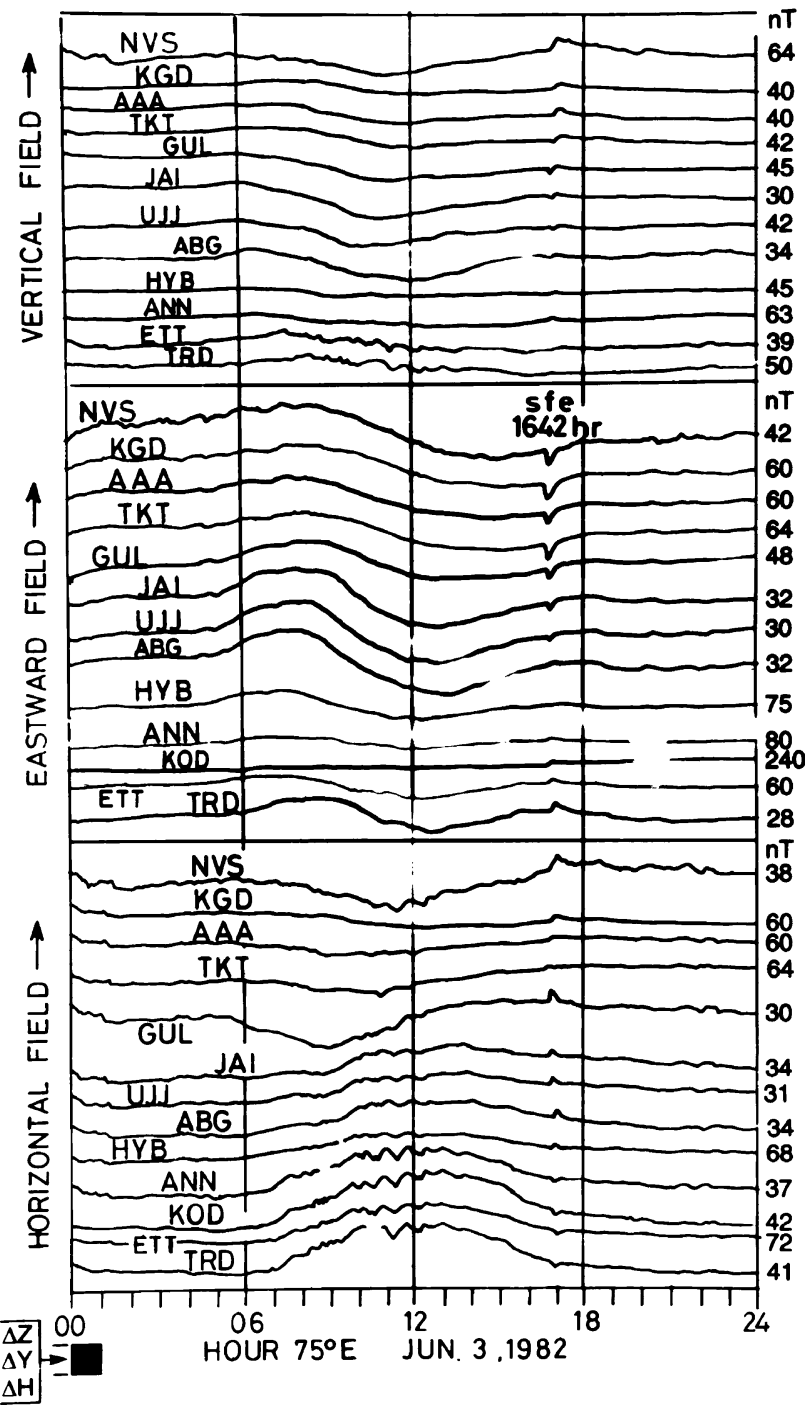

Fig. 13. Same as Fig. 6 but for 3 June 1982. Flare occurred at 1642 LT.

the normal electrojet times, the zonal current is eastward giving positive $\Delta H$ and the meridional current is away from the magnetic equator giving a negative $\Delta Y$. During the counter electrojet period, the zonal current is reversed to the westward direction giving a negative value of $\Delta H$; the meridional current associated with the electrojet is also reversed to equatorward direction giving a positive impulse in $\Delta Y$. The absence of strong effect in $\Delta Y$ due to solar flare during the counter electrojet time may be due to the cancellation of the effects of $S q$ and the electrojet components of the equatorial currents during that period. The solar flare effect in $Z$ during the counter electrojet period is interestingly the observation of abnormally large negative impulse at stations within the electrojet belt. This can be explained in terms of positive induction effect on $Z$ during normal electrojet and negative effect on $\Delta Z$ during counter electrojet times. Rastogi (1999) has described the effect of solar flares on the $H$ and $Y$ fields at Huancayo. During normal electrojet condition which consists of a positive impulse in $H$ and $Y$ and a negative impulse in $Z$ field. During counter electrojet periods a solar flare produced a negative impulse in $H$ and $Y$ fields and a positive 


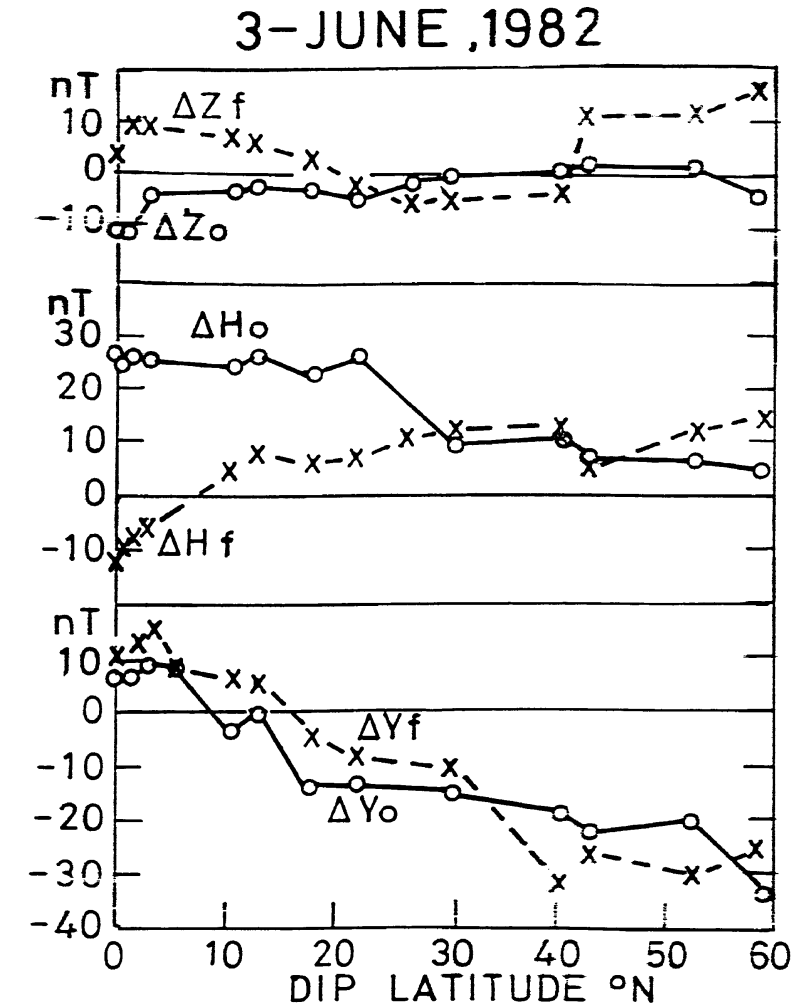

Fig. 14. Latitudinal variations of the pre-flare values $(\triangle H o, \Delta Y o$ and $\Delta Z o)$ and the peak flare impulses $(\Delta H f, \Delta Y f$ and $\Delta Z f)$ of the flare at 1642 LT on 3 June 1982 during a partial counter electrojet.

impulse in $Z$ field at Huancayo. Thus, it was shown that a flare effect is just an augmentation of both the zonal as well as the meridional components at the electrojet currents prevailing at pre-flare level. Their effect on the vertical field is also an increase of the existing field.

During the partial counter electrojet period when the westward current is not strong compared to the eastward one, the $s f e$ in $\Delta H$ may be a mere reduction in amplitude at the equatorial latitudes as in the case of flare on 3 May 1973 (Rastogi, 1996). Similarly, the $s f e$ in $\Delta Y$ and $\Delta Z$ may be different at the equatorial and at low latitude stations.

The results of flare effects in $Z$ included in Fig. 11 (15th June 1982) during the counter electrojet time show the positive magnitude upto the station at the latitude of JAI. However, at TRD to KOD stations which are very close to the axis of the electrojet, flare effects in $Z$ are negative or close to zero. Similar trends in $Z$ during partial counter electrojet time (refer to Fig. 14) are noticed but the positive variations, including the stations close to the electrojet axis, are confined upto the latitudes of ABG station. However, the latitudinal variation of $S q(Z)$ of the June month shown on the top panel of Fig. 5 has not shown any deviation from the seasonally expected pattern. Thus, it is quiet evident that the signs of $Z$ during the flare, the ambient pre-flare fields ( $Z o$ 's) and the associated electromagnetic induction effects will vary with the flare time equivalent current systems (not shown but can be considered by the magnitude and directions of changes in $H$ and $Y$ ). The counter and partial counter electrojet effects on the flare in $Z$ are quiet intriguing as the variations during these times are very different for latitudes far beyond the equatorial electrojet region. It is well known, the $Z$-component of the field is very sensitive to the local inhomogenities of the earth's internal conductivity. In the frequency intervals of the flares, the magnitudes of the induced components due to electromagnetic induction within the earth are not too small to be ignored. Also, during the flare, radiation of different wavelengths of varying intensities may be responsible for the additional ionization. Perhaps all these factors may have restricted the studies of $s f e$ effect on $Z$ so far.

The fact that magnitudes and the signs of flare and preflare fields, especially in the $Y$ and $Z$ components, indicates that simultaneous existence of zonal and meridional currents responsible for $S q$ and equatorial electrojet. These results further confirm the recent suggestion made by Rastogi (1996) that the solar flare effect on the meridional current at low latitudes consist of a component associated with the global $S q$ current and another component directly related with the electrojet current which may change direction depending on whether the electric field at $100 \mathrm{~km}$ is eastward or westward. Thus, this anomalous induction effect of $s f e$ in $Z$ extends to larger latitudinal belt than that of the induction effects with $S q(Z)$. During strong counter electrojet event, sfe produces a negative impulse at equatorial stations and positive impulse at higher latitudes. The $s f e$ in $Y$ at higher latitudes is a negative impulse but at equatorial latitudes the $s f e$ in $Y$ is small due to the cancellation of negative effect in $S q$ component by the positive impulse due to the electrojet component of ionospheric current at equatorial latitudes. The $s f e$ in $Z$ consists of a negative impulse at all latitudes.

During a partial counter electrojet event $s f e$ appear to be the combined effects on the $S q$ and electrojet components of the ionospheric currents especially on the relative strengths of the two currents depending upon the magnitude of the partial counter electrojet event.

These results confirm the existence of the zonal and meridional components of the ionospheric currents over the equatorial latitudes causing the daily $H$ and $D$ variations. Further at equatorial latitudes besides the global $S q$ currents, there exist zonal and meridional currents associated with the equatorial electrojet fields, which combine with the $S q$ currents to produce the complex effects.

Acknowledgments. The Editor thanks Dr. A. Saito and another referee for their assistance in evaluating this paper.

\section{References}

Carlo, L., B. P. Singh, R. G. Rastogi, and A. K. Agrarwal, The induced effects of geomagnetic variations in equatorial region, J. Geophys., 51, 199-205, 1982.

Carrington, R. C., Description of a singular appearance seen in the sun on Sep 1, 1859, Mon. Notic. Roy. Astron. Soc., 20, 13, 1859.

Dellinger, J. H, A new radio transmission phenomenon, Phys. Rev., 48, 705, 1935.

Fleming, J. A., Notes on radio fade-out of August 25, 1936, Terr. Magn. Atmos. Electr., 41, 404-436, 1936.

Forbush, S. E. and M. Casaverde, Equatorial Electrojet in Peru, 135 pp., C.I.W. Publ. No. 620, Washington D.C., 1961.

Fukushima, N., Transequatorial field-aligned currents at low latitudes and their possible connection with the equatorial electrojet, Brazilian Journal of Geophys., 11, 291-302, 1993.

Hodgson, R., On a curious appearance seen in the sun, Mon. Notic. Roy. Astron. Soc., 20, 15, 1859.

McNish, A. G., Terrestrial magnetic and ionospheric effects associated with 
bright chromospheric eruptions, Terr. Magn. Atmos. Electr., 42, 109-122, 1937.

Nagata, T., Characteristics of the solar flare effects (Sqa) on geomagnetic field at Huancayo (Peru) and at Kakioka (Japan), Terr. Magn. Atmos. Electr., 57, 1-14, 1952.

Nagata, T., Solar flare effect on the geomagnetic field, J. Geomag. Geoelectr., 18, 197-219, 1966.

Nityananda, N., A. K. Agarwal, and B. P. Singh, Induction at short periods in the horizontal fieldvariations in the Indian Peninsula, Phys. Earth Planet. Inter, 15, 5-9, 1977.

Ohshio, M., N. Fukushima, and T. Nagata, Solar flare effects on geomagnetic field, Rep. Ionos. Space Res. Japan, 21, 77-114, 1967.

Rajaram, M., B. P. Singh, N. Nityananda, and A. K. Agarwal, Effect of the presence of a conducting channel between India and Sri Lanka Island on the features of the equatorial electrojet, Geophys. J. R. Astr. Soc., 56, 127-138, 1979.

Raja Rao, K. S. and M. P. Rao, On the location of the ionospheric current system causing geomagnetic solar flare effects, J. Atmos. Sci., 20, 498 501,1963

Rangarajan, G. K. and R. G. Rastogi, Solar flare effect in equatorial magnetic field during morning counter electrojet, Ind. J. Rad. Space Phys., 10, 190192, 1981 .

Rastogi, R. G., Solar flare crochet and sudden commencement in $\mathrm{H}$ within the equatorial electrojet region, J. Atmos. Terr. Phys., 27, 663-668, 1965.

Rastogi, R. G., On the simultaneous existence of eastward and westward flowing equatorial electrojet currents, Proc. Ind. Acad. Sci., A81, 80-92, 1975.

Rastogi, R. G., Latitudinal extent of equatorial electrojet effects in Indian zone, Ann. Geophys., 9, 777-783, 1991.

Rastogi, R. G., Solar flare effects on zonal and meridional currents at the equatorial electrojet stations Annamalainagar, J. Atmos. Terr. Phys., 58, 1413-1420, 1996.

Rastogi, R. G., Meridional equatorial electrojet current in American sector,
Ann. Geophys., 17, 220-230, 1999.

Rastogi, R. G., M. R. Deshpande, and N. S. Sastri, Solar flare effect in equatorial counter electrojet current, Nature (London), 258, 218-219, 1975.

Rastogi, R. G., G. K. Rangarajan, A. Sen Gupta, K. N. Iyer, and G. D. Vyas, Solar flare of 6 Nov 1980 and associated ionospheric effects, Ind. J. Radio Space Phys., 13, 179-183, 1983.

Rastogi, R. G., D. R. K. Rao, S. Alex, B. M. Pathan, and T. S. Sastry, An intense SFE and SC event in geomagnetic $H, Y$ and $Z$ fields at the Indian Observatories, Ann. Geophys., 15, 1301-1308, 1997.

Richardson, R. S., The bright hydrogen eruption and radio fade out of April 8, 1936, Terr. Magn. Atmos. Electr., 41, 197-198, 1936.

Richmond, A. D. and S. V. Venkateswaran, Geomagnetic crochets and associated ionospheric current systems, Radio Sci., 6(2), 139-164, 1971.

Sastri, J. H., The geomagnetic solar flare of 6 July 1968 and its implications, Ann. Geophys., 31, 481-485, 1975.

Srivastava, B. J., The geomagnetic solar flare effect on the counter electrojet, J. Atmos. Terr. Phys., 36, 1571-1575, 1974.

Srivastava, B. J. and H. Abbas, An interpretation of the Induction arrows at Indian stations, J. Geomag. Geoelectr., 32(Suppl), 187-196, 1978.

Torreson, O. W., W. E. Scott, and H. E. Stanton, A conspicuous solar eruption on April 8, 1936 and simultaneous disturbances on magnetic, ionospheric and earth current records at Huancayo magnetic observatory, Terr. Magn. Atmos. Electr., 41, 199-201, 1936.

Van Saben, D., Ionospheric current systems of ten IGY solar flare effects, J. Atmos. Terr. Phys., 22, 32-42, 1961.

Veldkamp, J. and D. Van Saben, On the current system of solar flare effects, J. Atmos. Terr. Phys., 18, 192-202, 1960.

R. G. Rastogi (e-mail: parvs@prl.ernet.in), B. M. Pathan, D. R. K. Rao (e-mail: drkrao@iig.iigm.res.in), T. S. Sastry, and J. H. Sastri 